\title{
Nonpuerperal Uterine Inversion
}

\author{
${ }^{1}$ Parneet Kaur, ${ }^{2}$ Khushpreet Kaur, ${ }^{3}$ Arvinder Kaur, ${ }^{4}$ Beant Singh, ${ }^{5} \mathrm{~K}$ Manjit Mohi
}

\begin{abstract}
Inversion of uterus may be classified as puerperal or obstetric and nonpuerperal or gynecological. Nonpuerperal uterine inversion has been described as a rare occurrence and is usually precipitated by tumors sited at the fundus of the uterus which exert traction force to cause the inversion. We present a case of 50 years old $P_{3} L_{3}$ who presented as emergency in the Department of Obstetrics and Gynecology with $\mathrm{C} / \mathrm{C}$ of mass protruding out from vulva and bleeding per vaginum since 6 hours and was finally diagnosed as a case of chronic inversion uterus with prolapsed fundal submucosal fibroid. Myomectomy was done followed by hysterectomy and she had uneventful postoperative period.
\end{abstract}

Keywords: Nonpuerperal, Inversion, Fibroid.

How to cite this article: Kaur P, Kaur K, Kaur A, Singh B, Mohi KM. Nonpuerperal Uterine Inversion. J South Asian Feder Obst Gynae 2014;6(1):56-58.

\section{Source of support: Nil}

\section{Conflict of interest: None}

\section{INTRODUCTION}

Inversion of uterus is an unusual entity and may be classified as puerperal or obstetric and nonpuerperal or gynecological. Nonpuerperal uterine inversion has been described as a rare occurrence by several authors but how really rare is it has not been defined. However, the fact that many gynecologists might not see any in their entire practice gives a clue as to its infrequent nature. ${ }^{1,2}$ Chronic nonpuerperal uterine inversion is often associated with uterine pathology. Prolapsed fibroids tend to be the most common inciting factor with occasional reports of inversion associated with uterine neoplasm and endometrial polyps. The contributing factors proposed are: (1) sudden emptying of the uterus previously distended by tumor, (2) thinning of the uterine walls due to an intrauterine tumor and (3) dilatation of the cervix. ${ }^{3}$

\footnotetext{
${ }^{1,3}$ Associate Professor, ${ }^{2}$ Professor, ${ }^{4}$ Assistant Professor ${ }^{5}$ Professor and Head

${ }^{1-5}$ Department of Obstetrics and Gynecology, Government Medical College and Rajindra Hospital, Patiala, Punjab, India

Corresponding Author: Parneet Kaur, Associate Professor Department of Obstetrics and Gynecology, House No. 151 Punjabi Bagh, Near Klair Orthopaedic Center, Patiala-147001 Punjab, India, Phone: 9876726865, e-mail: parneetkd@ yahoo.co.in
}

\section{CASE REPORT}

A 50 years old female $\mathrm{P}_{3} \mathrm{~L}_{3}$ (last child birth -14 years back) with all vaginal deliveries was admitted as emergency in the Department of Obstetrics and Gynecology, GMC and Rajindra Hospital, Patiala, on 30-05-2012 at 9.30 pm with $\mathrm{C} / \mathrm{C}$ of mass protruding out from vulva and bleeding per vaginum since 6 hours. According to patient, the mass used to come out since 3 years while squatting and she was able to repose it back but this time she was not successful. There was $\mathrm{h} / \mathrm{o}$ postcoital bleeding.

On GPE - patient was pale, vitals were stable.

$\mathrm{P} / \mathrm{A}$ - abdomen was soft, there was tenderness and muscle guarding in lower abdomen.

$\mathrm{L} / \mathrm{E}$ - there was a hard, firm, large hemorrhagic mass lying outside the vulva $(18 \times 10 \mathrm{~cm})$. The external os was not visible. No cervical rim could be felt. It was concluded that there was uterine inversion with a prolapse of a huge submucosal fundal fibroid.

Under G/A reposition was tried but was not successful.

A provisional diagnosis of chronic inversion uterus with prolapsed fundal submucosal fibroid was made. She was investigated for major surgery. Her $\mathrm{Hb}$ came out to be $7 \mathrm{gm} \%$ and she was given 7 unit of packed cells. Otherwise, she was HIV negative, and her preoperatory work up was normal.

On her USG of pelvic region uterus and adenexa could not be identified at the normal site which raised the suspicion of inversion uterus. Under general anesthesia, we performed myomectomy followed by hysterectomy (Fig. 1).

- Step I - incision was made and fibroid removed (Fig. 2).

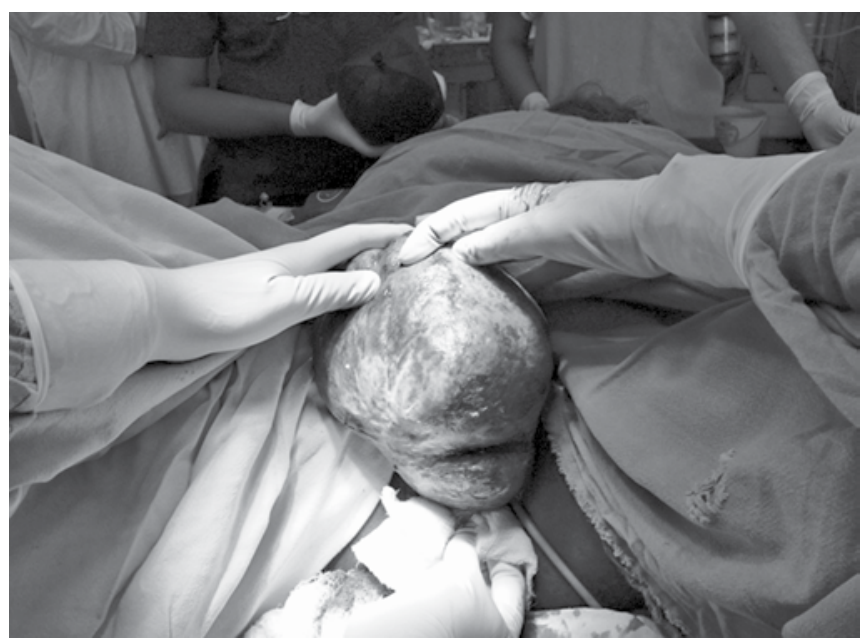

Fig. 1: A large mass protruding out of vulva before surgery 


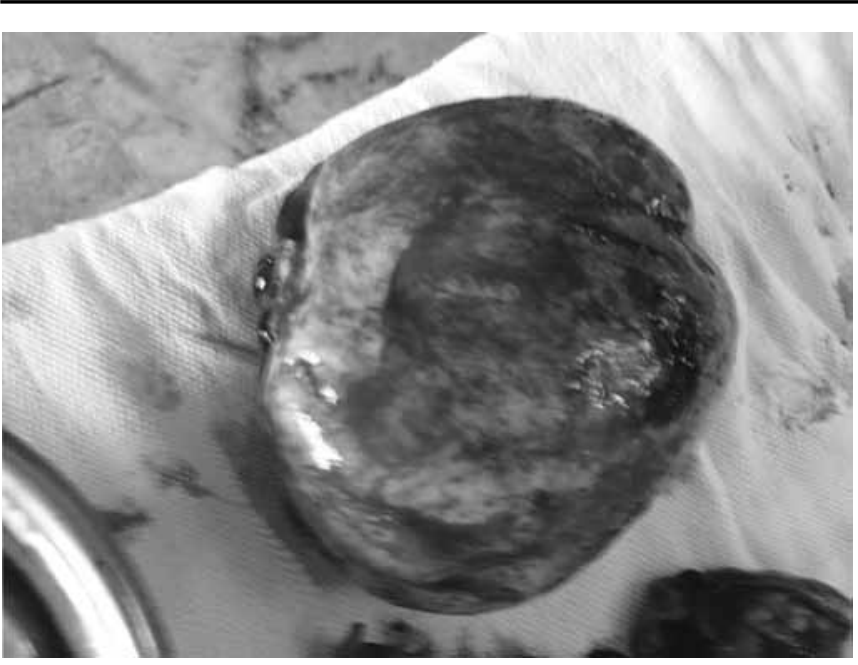

Fig. 2: The fibroid after myomectomy (weight approx. $900 \mathrm{gm}$ )

- Step II - extent of bladder determined.

- Step III - uterus was cut vertically posteriorly. Tubes and Ovarian ligaments identified and clamped. POD identified (no gut or omentum adhesions present).

- Step IV - clamped tissue ligated and cut.

- Step V - posterior incision of uterus extended anteriorly (POD checked thoroughly).

- Step VI - uterus was cut circumferentially (almost whole of cervix removed) (Fig. 3).

Hemostasis was ensured. Anterior, lateral and posterior vaginal walls were healthy. Aseptic vaginal packing was done, which was removed next day. Her postoperative period remained uneventful. Her histopathology report revealed leiomyoma with secondary degenerative changes.

\section{DISCUSSION}

Most cases of uterine inversion are puerperal and nonpuerperal uterine inversion is extremely rare. ${ }^{1,9}$ Nonpuerperal uterine inversion is usually precipitated by tumors sited at the fundus of the uterus which exert traction force to cause the inversion, although some cases have been reported with no association with tumors. ${ }^{2}$ Tibrewal $\mathrm{R}$ et al and Safdarin $\mathrm{L}$ et al each reported a case where patient presented as an emergency with similar complaints as ours. ${ }^{4,5}$ Takano et al summarized 88 cases of nonpuerperal inversion uterus: 81 $(92 \%)$ of these were associated with uterine tumor, of which $71.6 \%$ were leiomyomas and $20 \%$ were malignant. This emphasizes the need to perform biopsies prior to definitive treatment. ${ }^{8}$ Most cases of nonpuerperal uterine inversion are usually chronic, however, $8.6 \%$ of the cases are of acute onset as was our case. ${ }^{6}$ Uterine inversions can be classified as follows; Stage 1 - the inverted fundus remains in the uterine cavity; Stage 2 - complete inversion of the fundus through the cervix; Stage 3 - the inverted fundus protrudes through the vulva; Stage 4 - inversion of the uterus and the vaginal wall through the vulva. Nonpuerperal inversion can

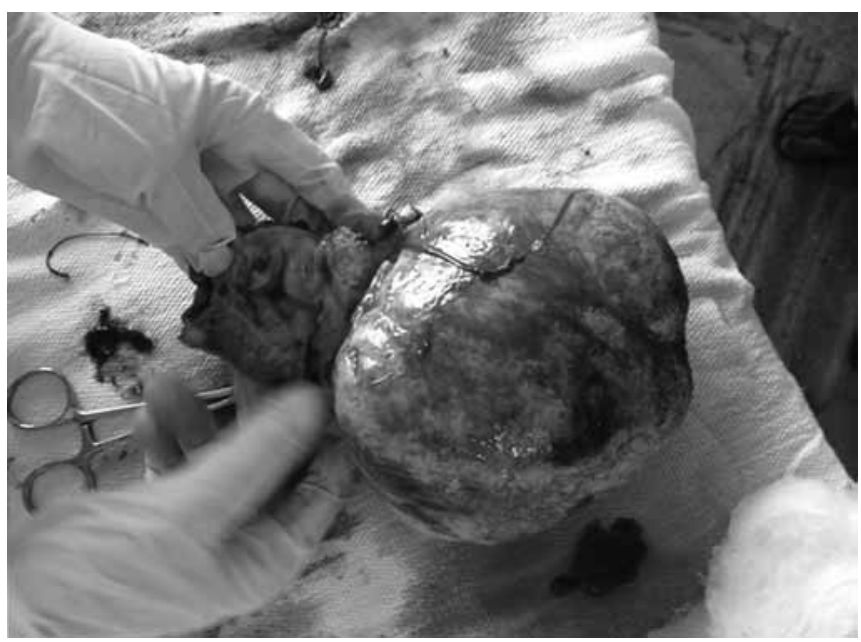

Fig. 3: The uterus and fibroid reconstructed after surgery

also be classified into acute and chronic uterine inversions. The diagnosis is easier with a stage 3 or 4 disease when a bluish-red mass is identified from the vulva. In other cases, the diagnosis can be difficult and the use of ultrasound or computerized tomography can be used. ${ }^{7}$

One case report confirms that diagnosis of inversion uterus may be difficult to make during examination. We noted two determining findings namely: (1) the uterus corpus could not be palpated on bimanual examination, (2) the cervix could not be visualized even after mass was removed.

Magnetic resonance imaging (MRI) and computerized tomography (CT) scan are useful diagnostic tools. MRI can examine the characteristic image of uterine inversion. A U-shaped uterine cavity and a thickened and inverted uterine fundus on a sagittal image and a 'bulls-eye' configuration on an axial image are signs indicative of uterine inversion. ${ }^{6}$ In our case, CT scan or MRI could not be done. In the present case, manual reposition was tried, after which surgical intervention was planned which confirmed the findings of Inversion uterus with a fibroid. Thus, myomectomy was done followed by vaginal hysterectomy.

The morbidity and mortality associated with uterine inversion correlate with the degree of hemorrhage, the rapidity of diagnosis and the effectiveness of treatment. ${ }^{4}$

\section{CONCLUSION}

Though nonpuerperal uterine inversion is uncommon, few cases will have to be managed without prior experience. High degree of suspicion for the diagnosis and clear knowledge about gynecological surgery will permit a successful outcome.

\section{REFERENCES}

1. Ganjooie TA. Nonpuerperal uterine inversion: a case report. Arch Iranian Med 2005;8(1):63-66.

2. Fofie CO, Baffoe P. Nonpuerperal uterine inversion: a case report. Ghana Med J 2010 June;44(2):79-81. 
3. Kilpatrick CC, Chohan L, Maier RC. Chronic nonpuerperal uterine inversion and necrosis: a case report. J Medical Case Reports 2010;4:381.

4. Tibrewal R, Goswami S, Chakravorty PS. Nonpuerperal uterine inversion. J Obstet Gynecol India 2012;62(4):452-453.

5. Safdarian L, Aleyassin A, Forootan M, Kamalian N, Ahmadzadeh A. Nonpuerperal uterine inversion: a case report. Acta Medica Iranica 2003;41(1):59-61.

6. Muhammad Z, Ibrahim SA, Yakasai IA. Chronic nonpuerperal uterine inversion: case series. Niger J Basic Clin Sci 2012;9:87-90.
7. Kr Koley A, Saha D, Saha A, Dey BC. Nonpuerperal uterine inversion: a rare complication of uterine leiomyoma. Journal of Evo-lution of Medical and Dental Sciences 2013;2(32):60386041.

8. Takano K, Ichikawa Y, Tsunoda H, Nishida M. Uterine inversion caused by uterine sarcoma: a case report. Jpn Clin Oncol 2001;31:39-42.

9. Simms-Stewart D, Frederick S, Fletcher H, Char G, Mitchell S. Postmenopausal uterine inversion treated by subtotal hysterectomy. J Obstet Gynaecol 2008;28:116-117. 